\title{
Effects of Abscisic Acid on Drought Responses of Kentucky Bluegrass
}

\author{
Zhaolong Wang, ${ }^{1}$ Bingru Huang, ${ }^{2}$ and Qingzhang $\mathbf{X u}^{3}$ \\ Department of Plant Biology and Pathology, Rutgers University, New Brunswick, NJ 08901
}

\begin{abstract}
AdDitional INDEX words. Poa pratensis, electrolyte leakage, photochemical efficiency, osmotic adjustment
Abstract. Abscisic acid (ABA) is an important hormone regulating plant response to drought stress. The objective of this study was to investigate effects of exogenous ABA application on turf performance and physiological activities of kentucky bluegrass (Poa pratensis L.) in response to drought stress. Plants of two kentucky bluegrass cultivars, 'Brilliant' (drought susceptible) and 'Midnight' (drought tolerant), were treated with ABA (100 $\mu \mathrm{M})$ or water by foliar application and then grown under drought stress (no irrigation) or well-watered (irrigation on alternate days) conditions in a growth chamber. The two cultivars responded similarly to ABA application under both watering regimes. Foliar application of ABA had no effects on turf quality or physiological parameters under well-watered conditions. ABA application, however, helped maintain higher turf quality and delayed the quality decline during drought stress, compared to the untreated control. ABA-treated plants exposed to drought stress had higher cell membrane stability, as indicated by less electrolyte leakage of leaves, and higher photochemical efficiency, expressed as Fv/Fm, compared to untreated plants. Leaf water potential was not significantly affected, whereas leaf turgor pressure increased with ABA application after 9 and $12 \mathrm{~d}$ of drought. Osmotic adjustment increased with ABA application, and was sustained for a longer period of drought in 'Midnight' than in 'Brilliant'. The results suggested that exogenous ABA application improved turf performance during drought in both drought-sensitive and tolerant cultivars of kentucky bluegrass. This positive effect of ABA could be related to increased osmotic adjustment, cell turgor maintenance, and reduced damage to cell membranes and the photosynthetic system.
\end{abstract}

Water availability is becoming increasingly limited for irrigation. Prolonged drought stress due to insufficient rainfall or irrigation can be detrimental for plant growth (Aronson et al., 1987; Beard, 1973; 1989; Huang and Gao, 1999). Therefore, improving drought resistance of plants by means of cultural practices and breeding becomes imperative for water conservation and maintenance of plant growth in water-limiting environments. This requires better understanding of physiological and biochemical factors involved in plant adaptations to drought stress.

Plant hormones, such as abscisic acid (ABA), play an important role in the regulation of plant tolerance to various environmental stresses, particularly drought stress (Quarrie, 1989, 1993). Endogenous ABA levels increase when plants are subjected to drought stress (Cao et al., 2000; Conti et al., 1994; Harris and Outlaw, 1991; Henson et al., 1981; Ilahi and Dorffling, 1982; Ivanovic et al., 1992). ABA accumulation has been found to protect plants from drought damage by inducing stomata closure to reduce water loss via transpiration (Borel et al., 1997; Li et al., 2000) and increasing hydraulic conductance for water movement from roots to leaves (Ludewig et al., 1988; Zhang et al., 1995). ABA inhibits leaf growth and reduces transpirational area, and thus can reduce water loss (Alves and Setter, 2000; Carrow, 1996; Sharp et al., 1994). ABA has also been found to induce the expression of some genes, which results in cellular changes that confer an ability to maintain cell turgor and withstand the damaging forces associated with reduced water potential and desiccation (Bray et al., 1999; Lebreton et al., 1995).

Exogenous application of ABA has been reported to improve drought tolerance in various plant species such as maize (Zea mays L.) (Bochicchio et al., 1991), pepper (Capsicum annuum L.)

Received for publication 15 Feb. 2002. Accepted for publication 9 Sept. 2002. ${ }^{1}$ Postdoctoral research associate.

${ }^{2}$ Associate professor and corresponding author; e-mail huang@ aesop.rutgers.edu. ${ }^{3}$ Research associate. Current address: Monsanto Company, GG5B, Chesterfield, MO 63198.
(Leskovar and Cantliffe, 1992), old jack pine (Pinus banksiana L.) (Rajasekaran and Blake, 1999), and Tradescantia virginiana L. (Franks and Farquhar, 2001). While the importance of ABA in drought regulation is widely recognized, information on how ABA affects drought resistance in turfgrasses is limited. Only a few studies on effects of ABA on turfgrass have been documented. Stahnke and Beard (1982) reported that exogenous application of ABA reduced transpiration of creeping bentgrass (Agrostis pulastris Huds.) by 59\%. Jiang and Huang (2002) found drought injury in tall fescue (Festuca arundinacea L.) was alleviated with foliar ABA application, which paralleled the delayed induction of protein synthesis. Understanding physiological effects of ABA on drought responses of turfgrass would help gain insight on drought resistance mechanisms, and would be important for water conservation in turfgrass management.

The objectives of this study were to examine how exogenous ABA application affects drought responses of two kentucky bluegrass cultivars differing in drought resistance, and to investigate whether the effects of $\mathrm{ABA}$ are related to the regulation of water relations, membrane protection, and/or photosynthetic activity. A relatively drought tolerant cultivar, 'Midnight', and a drought susceptible cultivar, 'Brilliant', of kentucky bluegrass were selected based on our previous studies (Wang and Huang, 2001).

\section{Materials and Methods}

Plant materials and growth conditions. Mature sods (15 $\mathrm{cm}$ in diameter and $2 \mathrm{~cm}$ deep) of both cultivars were collected from field plots at Adelphia Turfgrass Experiment Station, Rutgers University, New Jersey. Sods were washed free of soil before planting in 20-cm-diameter $\times 60$-cm-deep polyvinyl chloride tubes filled with a mixture of sand and top soil (fine, montmorillonitic, mesic, aquic arquidolls) (1:2, v/v). Plants were grown in a greenhouse for $60 \mathrm{~d}$ and then transferred to growth chambers with a temperature of $22 / 16^{\circ} \mathrm{C}$ (day/night), a 14-h photoperiod, 
and photosynthetically active radiation of $600 \mathrm{mmol} \cdot \mathrm{m}^{-2} \cdot \mathrm{s}^{-1}$. Grasses were well watered and maintained at the above conditions in the growth chambers for $15 \mathrm{~d}$ to allow adaptation to the growth-chamber conditions before drought treatment was imposed. Controlled-release fertilizer $(17 \mathrm{~N}-6 \mathrm{P}-10 \mathrm{~K})$ was topdressed twice to provide $\mathrm{N}$ at $50 \mathrm{~kg} \cdot \mathrm{ha}^{-1}$ prior to drought treatment. Turf was hand clipped twice weekly at a 6-cm height.

EXPERIMENTAL DESIGN AND TREATMENTS. For ABA treatment, $40 \mathrm{~mL}$ of $( \pm) \mathrm{ABA}(100 \mu \mathrm{m})$ solution were sprayed uniformly on a $0.32 \mathrm{~m}^{2}$ of foliage using a spray bottle at $1000 \mathrm{HR}$ once daily for a 3-d period before soil moisture treatments were initiated. A total of $3.3 \mathrm{mg}( \pm)$ ABA was applied per square meter turf area. The cost to treat the turf with $\mathrm{ABA}$ at the rates used in this study is about $\$ 0.033 / \mathrm{m}^{2}$ turf area based on the price of a commercial (+)ABA analog (S-ABA, \$20/g, Lomon Bio Technology, Chengdu, China). Plants untreated with ABA were sprayed with $40 \mathrm{~mL}$ of deionized water. Both ABA-treated and untreated plants were exposed to two moisture regimes.

A) Drought stress: irrigation was withheld for $30 \mathrm{~d}$.

B) Well-watered control: plants were irrigated every other day until drainage occurred from the bottom of the pot.

The experiment was a completely randomized design, with factorial arrangement (soil moisture, ABA, and cultivars). Each treatment had four replicates.

Measurements. Volumetric soil water content in 0 to $20 \mathrm{~cm}$ soil layer was monitored to determine soil dryness during drought stress by time domain reflectometry (TDR, Soil Moisture Equipment Corp., Santa Barbara, Calif.). The field capacity of the sand and topsoil mix was $26.8 \% \pm 0.5 \%$ (mean of eight replications \pm $\mathrm{SE}$ ), which was measured in 8 pots with TDR when drainage ceased following watering the soil to complete saturation. Soil water content declined to $15 \%$ by $12 \mathrm{~d}$ and $5 \%$ by $30 \mathrm{~d}$ of drought.

Several physiological measurements were made at 6-d intervals during the experiment. Turf quality was rated visually on the basis of color, uniformity, and density on a 0 to 9 scale where 0 = worst quality, $6=$ minimum acceptable quality, and $9=$ best quality. Vertical shoot extension rate was estimated by measuring the difference in the mean canopy height in 2-d intervals. The first and second youngest, fully expanded leaves from different plants in each pot were sampled to measure leaf water potential, osmotic potential, electrolyte leakage, and sugar content. Leaf water potential and osmotic potential were measured using a thermocouple psychrometer (Decagon Devices, Inc., Pullman, Wash.). Leaf turgor was calculated as the difference between leaf water potential and osmotic potential. Osmotic adjustment was calculated as the difference in osmotic potential at full turgor $\left(\Psi_{\pi 100}\right)$ between control and stressed plants $\left(\Psi_{\pi 0}\right)$ (Blum, 1989; Blum and Sullivan, 1986). Cell membrane stability was estimated by measuring electrolyte leakage (EL). A $0.1 \mathrm{~g}$ sample of leaves was rinsed and immersed in $20 \mathrm{~mL}$ of deionized water. The conductivity of the solution $\left(\mathrm{C}_{\text {initial }}\right)$ was measured after the leaves were shaken for $24 \mathrm{~h}$. Leaves were then killed by autoclaving at $140^{\circ} \mathrm{C}$ for $20 \mathrm{~min}$. The conductivity of killed tissues $\left(\mathrm{C}_{\max }\right)$ was measured after samples were cooled to room temperature. Relative EL was calculated as the percentage of $\mathrm{C}_{\text {initial }}$ over $\mathrm{C}_{\max }$. Leaf photochemical efficiency, expressed as the ratio of variable fluorescence to the maximum fluorescence $(\mathrm{Fv} / \mathrm{Fm})$ of chlorophyll, was determined weekly on 4 leaves in each pot with a fluorescence induction monitor (Dynamax, Houston, Texas).

The content of water soluble sugars was determined following the method described in Buysse and Merckx (1993). Fifty milligram of dry leaf powder was extracted with $80 \%$ (v/v) ethanol for three times $(20 \mathrm{~mL})$. The total volume of the combined and filtered extracts was adjusted to $100 \mathrm{~mL}$ using deionized water. One milliliter of samples was transferred into a glass tube, and 1 $\mathrm{mL} 18 \%(\mathrm{w} / \mathrm{v})$ phenol solution was then added. Immediately afterwards, $5 \mathrm{~mL}$ of concentrated sulphuric acid were added, the solution in the tube was mixed using a vortex mixer. Tubes were allowed to stand for $20 \mathrm{~min}$ and cooled down to room temperature before absorbance was measured with a spectrophotometer at 490 nm (Genesys, Spectronic Instruments, Inc., Rochester, N.Y.).

Statistical analysis. Effects of ABA, soil moisture, cultivar, and their interactions were determined using an analysis of variance according to the general linear model procedure of Statistical Analysis System (SAS Institute, Cary, N.C.). Each treatment mean was the average of four replications. Effects of ABA for each cultivar were analyzed by comparing to their respective untreated controls under well-watered or drought stress conditions at a given time of treatment. Differences among treatments and cultivars were determined by Tukey's studentized range test using the minimum significance difference (MSD) at the 0.05 probability level.

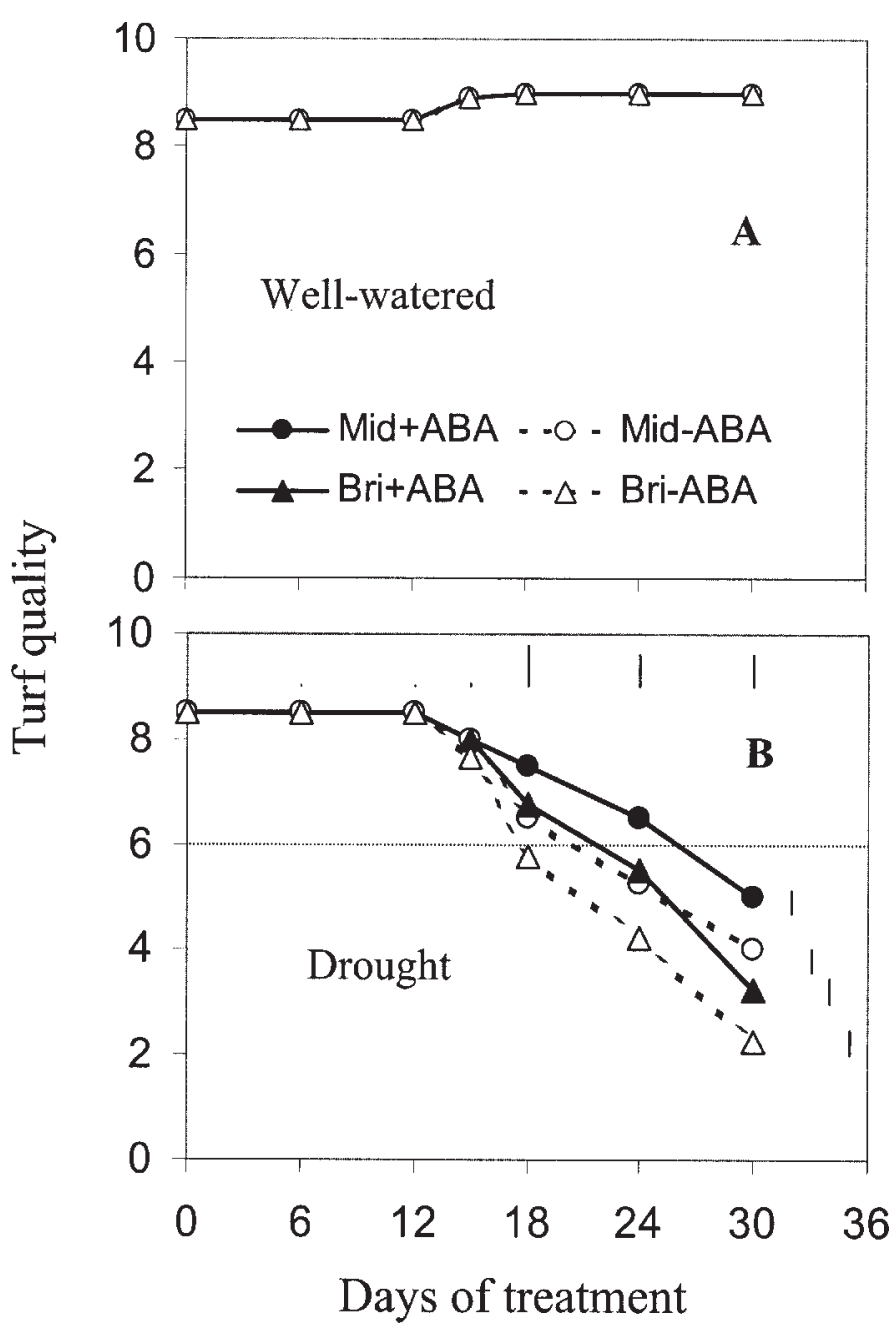

Fig. 1. Effects of ABA on turf quality in two kentucky bluegrass cultivars under well-watered (A) and drought (B) conditions. Mid+ABA: 'Midnight' with ABA application; Mid-ABA: 'Midnight' without ABA treatment; Bri+ABA: 'Brilliant' with ABA treatment; Bri-ABA: 'Brilliant' without ABA treatment. Vertical bars on the top indicate MSDs $(P=0.05)$ for treatment comparison at aiven day of drought. Vertical bars on the right indicate MSDs $(P=0.05)$ for turf quality comparison over time within the treatment. 


\section{Results}

TURF QUALITY. ABA application had no effect on turf quality in well-watered plants of either 'Brilliant' or 'Midnight' (Fig. 1A). Turf quality started to decline below the initial control level at $15 \mathrm{~d}$ of drought stress in both ABA-treated and untreated plants for both cultivars, and to below the minimum acceptable level (6.0) at $18 \mathrm{~d}$ for untreated 'Brilliant' and $24 \mathrm{~d}$ for untreated 'Midnight' (Fig. 1B). ABA application delayed the decline and maintained a better turf quality than untreated controls for both cultivars at 18,24 , and $30 \mathrm{~d}$ of drought stress. 'Midnight' exhibited higher quality than 'Brilliant' after $18 \mathrm{~d}$ of drought for both ABA-treated and untreated plants.

SHOOT GROWTH RATE. Vertical shoot extension rate of ABA-treated plants was less than that of the untreated plants for both cultivars only at $6 \mathrm{~d}$ of ABA application under well-watered conditions, but the growth rate recovered to the untreated level afterward (Fig. 2A). Shoot growth rate of both cultivars declined rapidly with drought (Fig. 2B). ABA application had no significant effects on shoot growth rate for either cultivar under drought conditions.

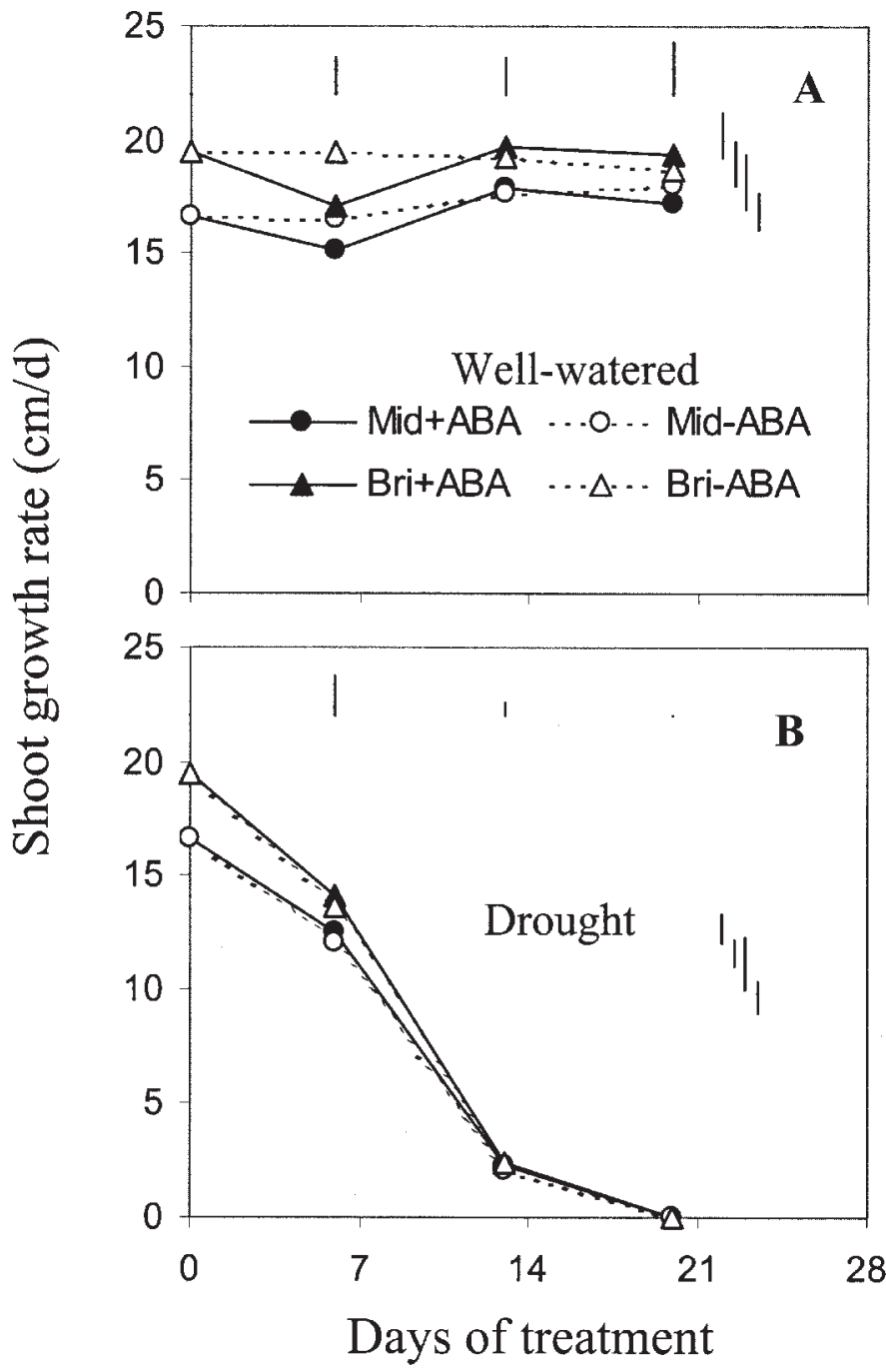

Fig. 2. Effects of ABA on shoot growth rate in two kentucky bluegrass cultivars under well-watered (A) and drought (B) conditions. Mid+ABA: 'Midnight' with ABA application; Mid-ABA: 'Midnight' without ABA treatment; Bri+ABA: 'Brilliant' with ABA treatment; Bri-ABA: 'Brilliant' without ABA treatment. Vertical bars on the top indicate MSDs $(P=0.05)$ for treatment comparison at a given day of drought. Vertical bars on the right indicate MSDs $(P=0.05)$ for comparison over time within the treatment.
Electrolyte Leakage. Electrolyte leakage (EL) was not affected by ABA application under well-watered conditions (Fig. $3 \mathrm{~A})$. Under drought conditions, however, ABA application reduced EL in both cultivars, to a greater extent for 'Brilliant' than for 'Midnight' at 18, 24, and $30 \mathrm{~d}$ of treatment (Fig. 3B). During drought stress, EL of 'Brilliant' increased sharply above the initial level at $12 \mathrm{~d}$, while EL of 'Midnight' did not show a significant increase until $24 \mathrm{~d}$ of stress in both ABA treated and untreated plants. 'Midnight' had lower EL than 'Brilliant' in either ABA-treated or untreated plants after $18 \mathrm{~d}$ of drought.

Photochemical efficiency $(\mathbf{F v} / \mathbf{F m})$. No difference in Fv/Fm ratio was detected between cultivars and $\mathrm{ABA}$ applications under well-watered conditions (Fig. 4A). Drought stress caused a significant decline in Fv/Fm ratio, beginning $18 \mathrm{~d}$ for 'Brilliant' and $24 \mathrm{~d}$ for 'Midnight' in ABA-untreated plants (Fig. 4B). The decline in the $\mathrm{Fv} / \mathrm{Fm}$ ratio was greater for 'Brilliant' than for 'Midnight'. ABA application delayed the decline of Fv/Fm ratio during drought stress and maintained a higher Fv/Fm ratio than the untreated control, for both cultivars, especially for 'Brilliant' at $18 \mathrm{~d}$ of stress (Fig. 4B).

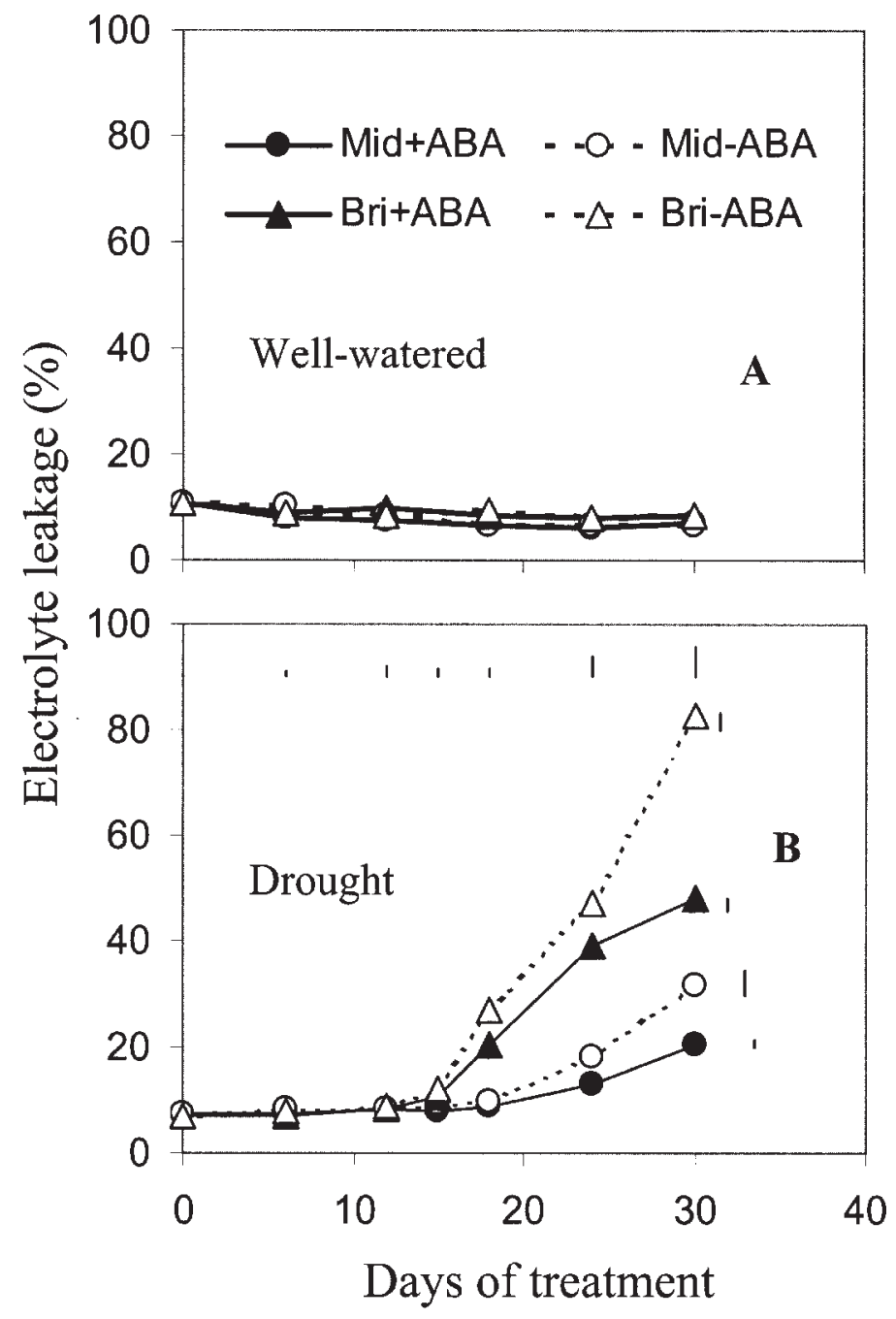

Fig. 3. Effects of ABA on leaf electrolyte leakage in two kentucky bluegrass cultivars under well-watered (A) and drought (B) conditions. Mid+ABA: 'Midnight' with ABA application; Mid-ABA: 'Midnight' withoutABA treatment; Bri+ABA: 'Brilliant' with ABA treatment; Bri-ABA: 'Brilliant' without ABA treatment. Vertical bars on the top indicate MSDs $(P=0.05)$ for treatment comparison at given day of treatment. Vertical bars on the right indicate MSDs $(P=0.05)$ for electrolyte leakage comparison over time within the treatment. 

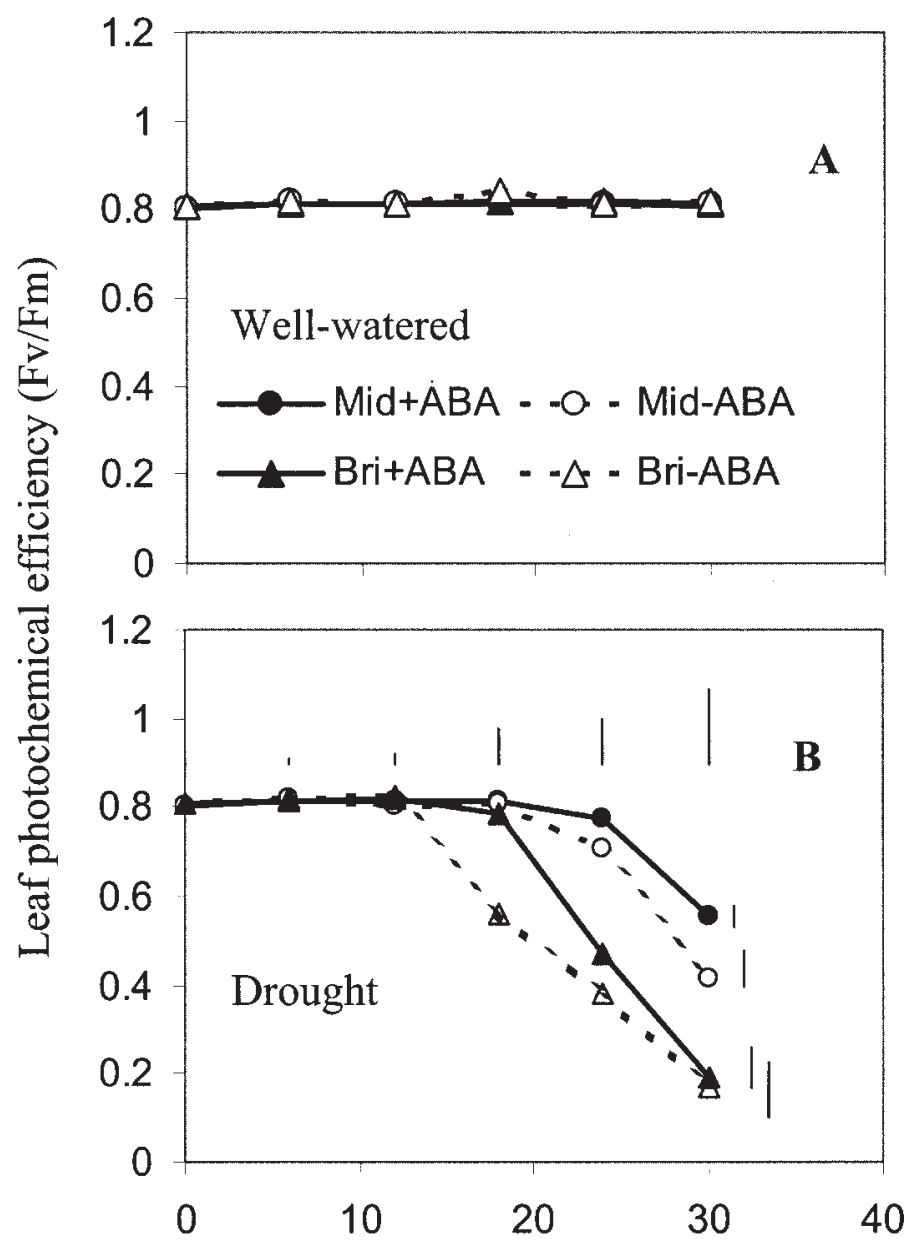

Days of treatment

Fig. 4. Effects of ABA on leaf photochemical efficiency in two kentucky bluegrass cultivars under well-watered (A) and drought (B) conditions. Mid+ABA: 'Midnight' with ABA application; Mid-ABA: 'Midnight' without ABA treatment; Bri+ABA: 'Brilliant' with ABA treatment; Bri-ABA: 'Brilliant' without ABA treatment. Vertical bars on the top indicate MSDs $(P=0.05)$ for treatment comparison at a given day of treatment. Vertical bars on the right indicate MSDs $(P=0.05)$ for $\mathrm{Fv} / \mathrm{Fm}$ ratio comparison over time within the treatment.

WATER RELATIONS. Leaf water potential ( $\left.\Psi_{\text {leaf }}\right)$ and leaf turgor pressure $\left(\Psi_{\mathrm{p}}\right)$ of both cultivars declined with drought stress (Table 1). The decline for both $\Psi_{\text {leaf }}$ and $\Psi_{\mathrm{p}}$ was greater for 'Brilliant' than 'Midnight'. ABA application increased $\Psi_{\text {leaf }}$ at 12 $\mathrm{d}$ of drought for 'Midnight' and $9 \mathrm{~d}$ for 'Brilliant', but had no significant effects on $\Psi_{\text {leaf }}$ at others days of drought for both cultivars. ABA application helped maintain higher $\Psi_{\mathrm{p}}$ at 9 and 12 $\mathrm{d}$ of drought for 'Midnight' and 6, 9, and $12 \mathrm{~d}$ for 'Brilliant'.

ABA application increased osmotic adjustment (OA) of both cultivars during drought stress compared to their respective, untreated controls (Fig. 5A and B). Increased OA with ABA exhibited at 4, 6, and $12 \mathrm{~d}$ of drought for 'Brilliant' (Fig. 5A) and 12, 18, 24, and $30 \mathrm{~d}$ for 'Midnight' (Fig. 5B).

Soluble SUgar CONTENT. Water soluble sugar content increased with drought progression, beginning at $18 \mathrm{~d}$ for 'Brilliant' and $24 \mathrm{~d}$ for 'Midnight' (Fig. 6). The increases were less pronounced for ABA-treated than untreated plants for both cultivars. ABA-treated plants had higher soluble sugar content than untreated plants at $6 \mathrm{~d}$ of treatment in both cultivars under both wellwatered (Fig. 6A) and drought conditions (Fig. 6B), but lower soluble sugar content at 18,24 , and $30 \mathrm{~d}$ of drought.

\section{Discussion}

Cultivars generally did not differ in their responses to ABA application, although 'Midnight' was more tolerant to drought than 'Brilliant', as indicated by its higher turf quality, $\Psi_{\text {leaf }}, \mathrm{Fv} / \mathrm{Fm}$ ratio, and lower EL. Exogenous ABA application improved turf quality, but had no significant effect on shoot growth rate for either 'Midnight' or 'Brilliant' under prolonged drought stress. Shoot growth ceased after $18 \mathrm{~d}$ of drought stress for both ABAtreated and untreated plants.

ABA application suppressed the increases in EL and the decline in $\mathrm{Fv} / \mathrm{Fm}$, suggesting that $\mathrm{ABA}$ could reduce drought injury by protecting cell membrane and photosynthesis apparatus. Rajasekaran and Blake (1999) reported that old jack pine seedlings treated with ABA maintained a higher photosynthetic rate and had lower EL than untreated plants. They found that the protective action of $\mathrm{ABA}$ on membrane integrity was associated with an inhibition of ethylene evolution during drought stress. Another protective process induced by ABA is the synthesis of dehydrin proteins (Bray, 1993; Chandler and Robertson, 1994; Close, 1996; Landi et al., 2001). These protective proteins can enhance water binding and ion-sequestering properties that allow them to interact with enzymes and other cell constitutes in such a way that their critical functions are preserved during drought stress (Campalans et al., 1999; Cellier et al., 1998; Lorenzo et al., 2001; Neill and Burnett, 1999; Tamminen et al., 2001; Wood and Goldsbrough, 1997). Jiang and Huang (2002), however, found that ABA-enhanced drought tolerance was not related to the induction of dehydrin in tall fescue, but increased water retention.

Osmotic adjustment facilitates the maintenance of water re-

Table 1. Effects of ABA on leaf water potential and turgor pressure under drought conditions.

\begin{tabular}{|c|c|c|c|c|c|c|c|c|}
\hline \multirow{3}{*}{$\begin{array}{l}\text { Days of } \\
\text { drought }\end{array}$} & \multicolumn{4}{|c|}{$\begin{array}{l}\text { Leaf water potential } \\
\qquad(\mathrm{MPa})\end{array}$} & \multicolumn{4}{|c|}{$\begin{array}{l}\text { Turgor pressure } \\
\qquad(\mathrm{MPa})\end{array}$} \\
\hline & \multicolumn{2}{|c|}{ Midnight } & \multicolumn{2}{|c|}{ Brilliant } & \multicolumn{2}{|c|}{ Midnight } & \multicolumn{2}{|c|}{ Brilliant } \\
\hline & $+\mathrm{ABA}$ & $-\mathrm{ABA}$ & $+\mathrm{ABA}$ & $-\mathrm{ABA}$ & $+\mathrm{ABA}$ & $-\mathrm{ABA}$ & $+\mathrm{ABA}$ & $-\mathrm{ABA}$ \\
\hline 0 & $-0.82 \mathrm{a}^{\mathrm{z}}$ & $-0.82 \mathrm{a}$ & $-0.70 \mathrm{a}$ & $-0.70 \mathrm{a}$ & $0.86 \mathrm{~b}$ & $0.86 \mathrm{~b}$ & $1.09 \mathrm{a}$ & $1.09 \mathrm{a}$ \\
\hline 6 & $-0.88 \mathrm{a}$ & $-0.91 \mathrm{a}$ & $-0.80 \mathrm{a}$ & $-0.89 \mathrm{a}$ & $1.04 \mathrm{a}$ & $1.09 \mathrm{a}$ & $1.06 \mathrm{a}$ & $1.12 \mathrm{~b}$ \\
\hline 9 & $-0.90 \mathrm{a}$ & $-1.12 \mathrm{a}$ & $-0.86 \mathrm{a}$ & $-1.13 b$ & $0.95 \mathrm{a}$ & $0.76 \mathrm{~b}$ & $1.16 \mathrm{a}$ & $0.99 b$ \\
\hline 12 & $-1.31 \mathrm{a}$ & $-1.57 \mathrm{~b}$ & $-2.02 \mathrm{a}$ & $-2.05 \mathrm{a}$ & $0.57 \mathrm{a}$ & $0.45 \mathrm{~b}$ & $0.15 \mathrm{a}$ & $0.037 \mathrm{~b}$ \\
\hline 16 & $-2.02 \mathrm{a}$ & $-2.07 \mathrm{a}$ & $-2.58 \mathrm{a}$ & $-2.86 \mathrm{a}$ & 0.00 & 0.00 & 0.00 & 0.00 \\
\hline MSD & 0.33 & 0.38 & 0.46 & 0.32 & 0.11 & 0.19 & 0.18 & 0.17 \\
\hline
\end{tabular}

$\overline{\mathrm{z}}$ Means followed by the different letters within a row indicate significant differences between $+\mathrm{ABA}$ and $-\mathrm{ABA}$ treatments for a given cultivar based on Tukey's test of MSD at $P=0.05$. The MSD values $(P=0.05)$ were for the comparison over time within $+\mathrm{ABA}$ or $-\mathrm{ABA}$ treatment. 
tention and cell turgor through accumulation of organic or inorganic solutes (Guicherd et al., 1997; Ranney et al., 1991; Wang et al., 1995; Zhang and Archbold, 1993), thus protecting tissues from desiccation as water potentials decrease (Bohnert et al., 1995; Bray, 1993). ABA application enhanced osmotic adjustment in both kentucky bluegrass cultivars, but increased OA with ABA were sustained for a longer period of drought for droughttolerant 'Midnight' than sensitive 'Brilliant'. This result suggests that enhanced OA with ABA could be a critical factor in regulating drought tolerance of kentucky bluegrass. This could contribute to the higher turgor pressure of leaves treated with ABA compared to those of untreated leaves in both cultivars. Enhanced plant tolerance associated with ABA to salinity stress has been related to the stimulation of osmotic adjustment in Phaseolus vulgaris L. (Cachorro et al., 1995).

Water soluble sugars have been found to be associated with osmotic adjustment in response to water stress in some plant species (Munns and Weir, 1981; Ranney et al., 1991; Tan et al., 1992; Zhang and Archbold, 1993). In the present study, ABA application induced a significant increase of soluble sugar con-

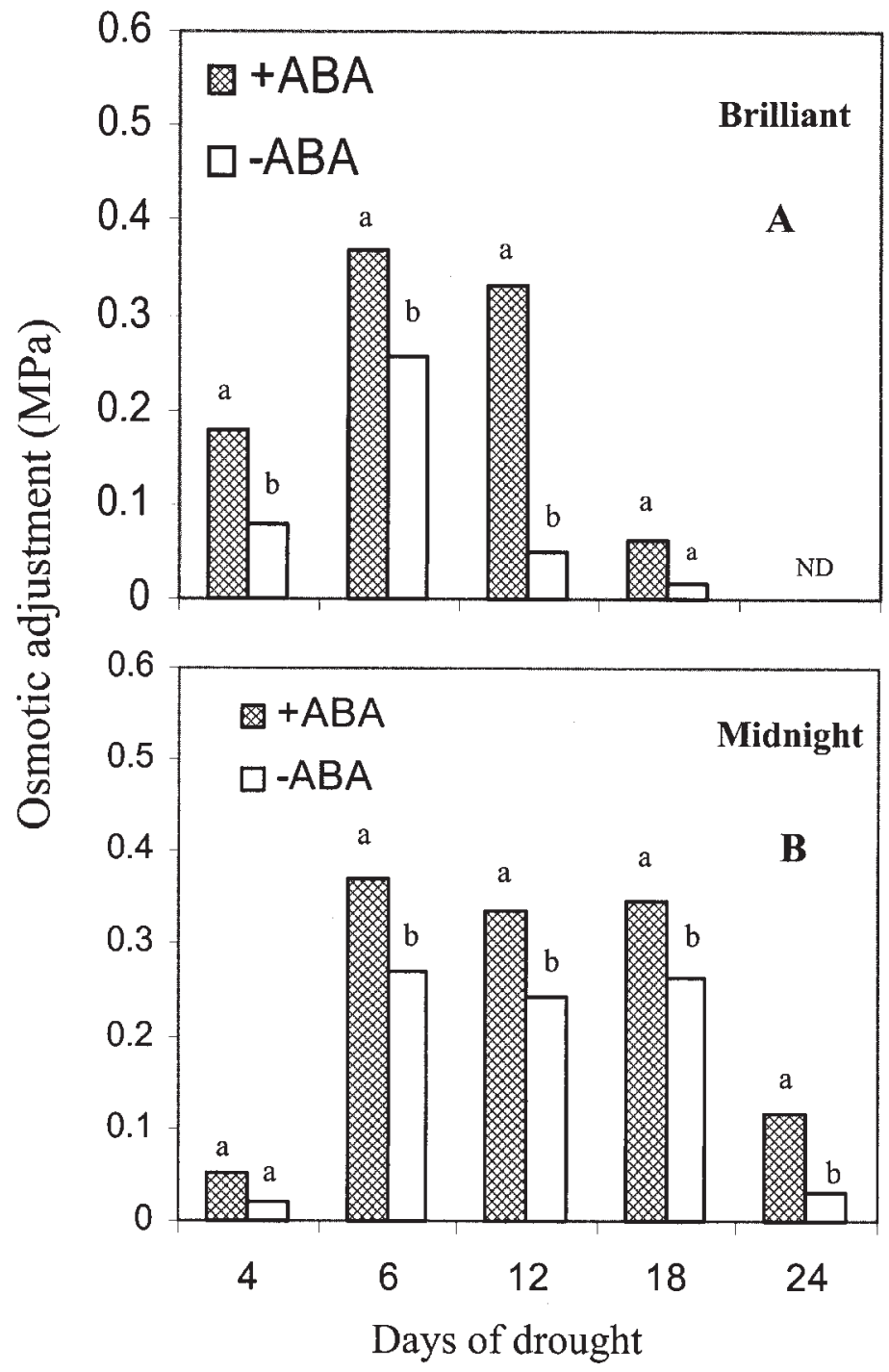

Fig. 5. Effects of ABA on osmotic adjustment under drought stress in two kentucky bluegrass cultivars. Columns marked with different letters indicate a significant difference between ABA-treated and untreated plants at a given day of treatment (MSD at $P=0.05$ ). tent only at $6 \mathrm{~d}$ in both well watered and drought conditions. Under prolonged and severe drought stress conditions, soluble sugar content, however, was higher in untreated than ABAtreated plants and in the drought sensitive cultivar than in the tolerant cultivar. Therefore, increased osmotic adjustment during prolonged, severe drought was not related to soluble sugar accumulation in this study, which could be due to accumulation of other solutes. Barathi et al. (2001) found that increases in soluble sugar content during prolonged drought stress was accompanied by decreases of starch, proteins, and nucleic acids, which indicates drought injury. In the present study, increases in soluble sugar content occurred after $18 \mathrm{~d}$ of drought for 'Brilliant' and $24 \mathrm{~d}$ for 'Midnight' when soil water was nearly depleted, which was coincident with the increases in EL and decreases in turf quality, indicating that soluble sugar increase in this stage could be associated with cell damage and leaf senescence.

In conclusion, exogenous application of ABA improved drought tolerance for both cultivars of kentucky bluegrass in our controlled environment study. The enhanced drought tolerance could result from increased cell membrane stability and photochemical

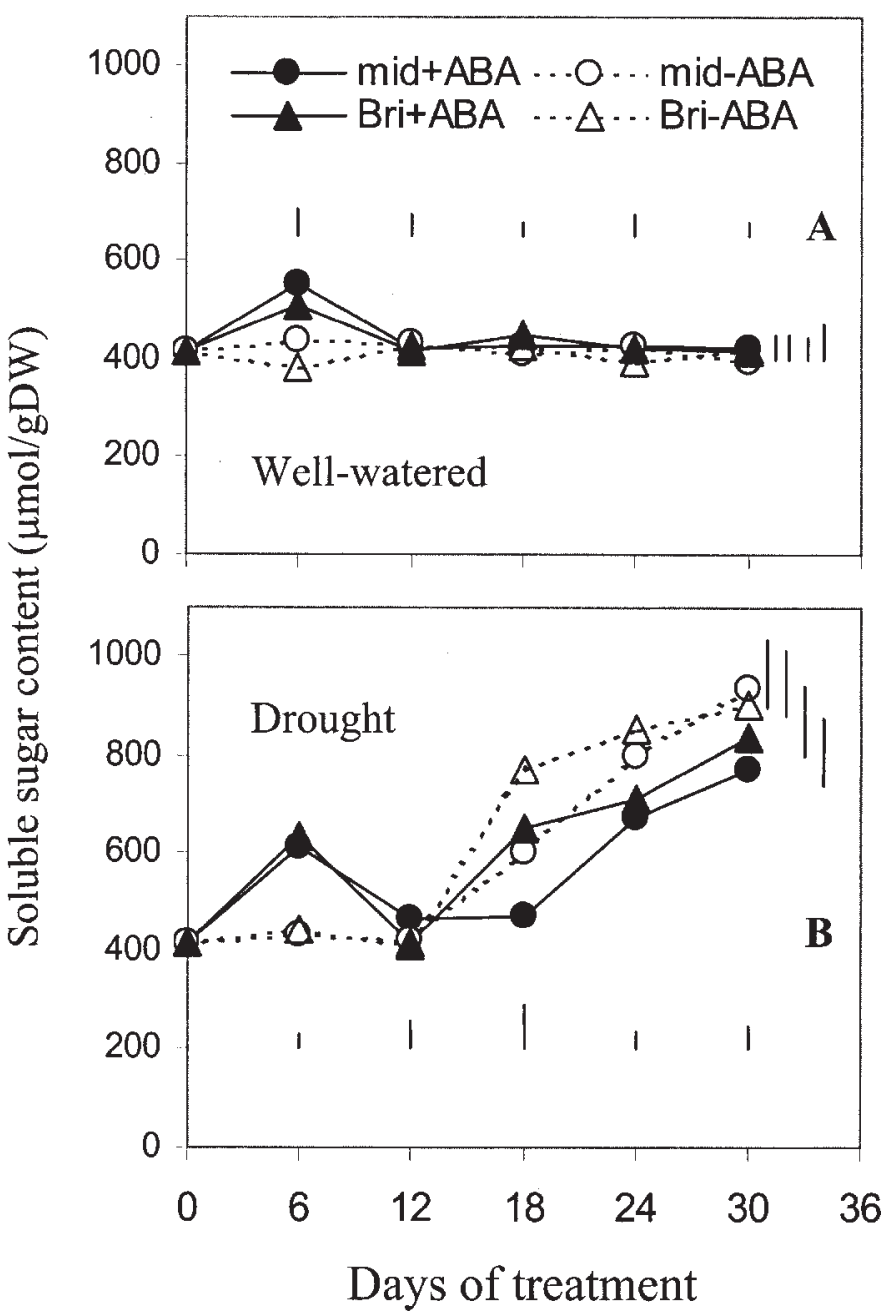

Fig. 6. Effects of ABA on water-soluble sugar content in two kentucky bluegrass cultivars under well-watered (A) and drought (B) conditions. Mid+ABA: 'Midnight' with ABA application; Mid-ABA: 'Midnight' without ABA treatment; Bri+ABA: 'Brilliant' with ABA treatment; Bri-ABA: 'Brilliant' without ABA treatment. Vertical bars on the top indicate MSDs $(P=0.05)$ for treatment comparison at a given day of treatment. Vertical bars on the right indicate MSDs $(P=0.05)$ for soluble sugar comparison over time within the treatment. 
efficiency, and turgor maintenance associated with osmotic adjustment. Field research is in progress to confirm the effects of ABA on drought tolerance in several turfgrass species under natural environmental conditions.

\section{Literature Cited}

Alves, A.A.C. and T.L. Setter. 2000. Response of cassava to water deficit: Leaf area growth and abscisic acid. Crop Sci. 40:131-137.

Aronson, L.J., A.J. Gold, and R.J. Hull. 1987. Cool-season turfgrass responses to drought stress. Crop Sci. 27:1261-1266.

Barathi, P., D Sunder, and AR Reddy. 2001. Changes in mulberry leaf metabolism in response to water stress. Biol. Plant. 44: 83-87.

Beard, J.B. 1973. Turfgrass: Science and culture. Prentice-Hall, Englewood Cliffs, N.J.

Beard, J.B. 1989. Turfgrass water stress: Drought resistance components, physiological mechanism, and species-cultivar diversity, p. 23-28. In H. Takatoh (ed.).Proc. $6^{\text {th }}$ Intl. Turf. Sci., Tokyo, Japan.

Blum, A. 1989. Osmotic adjustment and growth of barley genotypes under drought stress. Crop Sci. 29:230-233.

Blum, A. and C.Y. Sullivan. 1986. The comparative drought resistance of landraces of sorghum and millet from dry and humid regions. Ann. Bot. 57:838846.

Bochicchio, A., C. Vazzana, R. Velasco, M. Singh, D. Bartels. 1991. Exogenous $\mathrm{ABA}$ induces desiccation tolerance and leads to the synthesis of specific gene transcripts in immature embryos of maize. Maydica 36:11-16.

Bohnert, H.J., D.E.Nelson, and R.G.Jensen. 1995. Adaptations to environmental stresses. Plant Cell 7:1099-1111.

Borel, C., T. Simonneau, D. This, and F. Tardieu. 1997. Stomatal conductance and ABA concentration in the xylem sap of barley lines of contrasting genetic origins. Austral. J. Plant. Physiol. 24:607-615.

Bray, E.A. 1993. Molecular responses to water deficit. Plant Physiol. 103:10351040.

Bray, E.A., Tung Yuan Shih, M.S. Moses, A. Cohen, R. Imai, and A.L. Plant. 1999. Water-deficit induction of a tomato $\mathrm{H} 1$ histone requires abscisic acid. Plant Growth Regul. 29:35-46.

Buysse, J. and R. Merckx. 1993. An improved colorimetric method to quantify sugar content of plant tissue. J. Expt. Bot. 44:1627-1629.

Cachorro, P., R. Martinez, A. Ortiz, and A. Cerda. 1995. Abscisic acid and osmotic relations in Phaseolus vulgaris L. shoots under salt stress. J. Plant Growth Regul. 14:99-104.

Campalans, A., R. Messaguer, A. Goday, and M. Pages. 1999. Plant response to drought, from $\mathrm{ABA}$ signal transduction events to the action of the induced proteins. Plant Physiol. Biochem. 37:327-340.

Cao, W.X., Z.L. Wang, and T.B. Dai. 2000. Changes in levels of endogenous plant hormones during floret development in wheat genotypes of different spike sizes. Acta Bot. Sin. 42:696-700.

Carrow, R.N. 1996. Drought avoidance characteristics of diverse tall fescue cultivars. Crop Sci. 36:371-377.

Cellier, F., G. Conejero, J.C. Breitler, and F. Casse. 1998. Molecular and physiological responses to water deficit in drought-tolerant and drought-sensitive lines of sunflower. Plant Physiol. 116:319-328.

Chandler, P.M. and M. Robertson. 1994. Gene expression regulated by abscisic acid and its relation to stress tolerance. Annu. Rev. Plant Physiol. Plant Mol. Biol. 45:113-141

Close, T.J. 1996. Dehydrins: Emergence of a biochemical role of a family of plant dehydration proteins. Physiol. Plant. 97:795-803.

Conti, S., P. Landi, M.C. Sanguineti, S. Stefanelli, and R. Tuberosa. 1994. Genetic and environmental effects on abscisic acid accumulation in leaves of field-grown maize. Euphytica 78:81-89.

Franks, P.J. and G.D. Farquhar. 2001. The effect of exogenous abscisic acid on stomatal development, stomatal mechanics, and leaf gas exchange in Tradescantia virginiana. Plant Physiol. 125:935-942.

Guicherd, P., J.P. Peltier, E. Gout, R. Bligny, and G. Marigo. 1997. Osmotic adjustment in Fraxinus excelsior L.: Malate and mannitiol accumulation in leaves under drought conditions. Trees 11:155-161.

Harris, M.J. and W.H. Outlaw, Jr. 1991. Rapid adjustment of guard-cell abscisic acid levels to current leaf-water status. Plant Physiol. 95:171-173.

Henson, I.E., V. Mahalakshmi, F.R. Bidinger, and G. Alagarswamy. 1981. Genotypic variation in pearl millet (Pennisetum americanum (L.) Leeke), in the ability to accumulate abscisic acid in response to water stress. J. Expt. Bot. 32:899-910.

Huang, B. and H. Gao. 1999. Physiological responses of diverse tall fescue cultivars to drought stress. HortScience 34:897-901.

Ilahi, I. and K. Dorffling. 1982. Changes in abscisic acid and proline levels in maize varieties of different drought resistance. Physiol. Plant. 55:129-135.

Ivanovic, M., S.A. Quarrie, J. Djordjevic, and S. Pekic. 1992. Inheritance of abscisic acid production in maize (Zea mays L.) leaves in response to rapid drought stress and in the field. Maydica 37:313-318.

Jiang, Y. and B. Huang. 2002. Protein alterations in tall fescue in response to drought stress and abscisic acid. Crop Sci. 42:202-207.

Landi, P., M.C. Sanguineti, S. Conti, and R. Tuberosa. 2001. Direct and correlated responses to divergent selection for leaf abscisic acid concentration in two maize populations. Crop Sci. 41:335-344.

Lebreton, C., V. Lazic-Jancic, A. Steed, S. Pekic, and S.A. Quarrie. 1995. Identification of QTL for drought responses in maize and their use in testing causal relationships between traits. J. Expt. Bot. 46:853-865.

Leskovar, D.I. and D.J. Cantliffe. 1992. Pepper seedling growth response to drought stress and exogenous abscisic acid. J. Amer. Soc. Hort. Sci. 117:389393.

Li, J., X.Q. Wang, M.B. Watson, and S.M. Assmann. 2000. Regulation of abscisic acid-induced stomatal closure and anion channels by guard cell AAPK kinase. Science 287: 300-303.

Lorenzo, O., D. Rodriguez, G. Nicolas, P.L. Rodriguez, and C. Nicolas. 2001. A new protein phosphatase $2 \mathrm{C}$ (FsPP2C1) induced by abscisic acid is specifically expressed in dormant beechnut seeds. Plant Physiol. 125:1949-1956.

Ludewig, M., K. Doerffling, and H. Seifert. 1988. Abscisic acid and water transport in sunflowers. Planta 175:325-333.

Munns, R. and R. Weir. 1981. Contribution of sugars to osmotic adjustment in elongation and expanded zones of wheat leaves during moderate water deficits at two light levels. Austral. J. Plant Physiol. 8:93-105.

Neill, S.J. and E.C. Burnett. 1999. Regulation of gene expression during water deficit stress. Plant Growth Regul. 29:23-33.

Quarrie, S.A. 1989. Abscisic acid as a factor in modifying drought resistance, $\mathrm{p}$. 27-37. In: Environmental stress in plants: Biochemical and physiological mechanism. Springer-verlag, Berlin, Germany.

Quarrie S.A. 1993. Understanding plant responses to stress and breeding for improved stress resistance-The generation gap. In: T.J. Close and E.A. Bray (eds.). Plant responses to cellular dehydration during environmental stress. Curr. Topics in Plant Physiol. Ser. vol. 10. Amer. Soc. Plant Physiol., Rockville, Md. Rajasekaran, L.R. and T.J. Blake. 1999. New plant growth regulators protect photosynthesis and enhance growth under drought of jack pine seedlings. J. Plant Growth Regul. 18:175-181.

Ranney, T.G., N.L. Bassuk, and T.H. Whitlow. 1991. Osmotic adjustment and solute constituents in leaves and roots of water-stressed cherry (Prunus) trees. J. Amer. Soc. Hort. Sci. 116:684-688

Sharp, R.E., Y. Wu, G.S. Voetberg, I.N. Saab, and M.E. LeNoble. 1994. Comfirmation that abscisic acid accumulation is required for maize primary root elongation at low water potentials. J. Expt. Bot. 45:1743-1751.

Stahnke, G.K. and J.B. Beard. 1982. An assessment of antitranspirants on creeping bentgrass and bermudagrass turfs. Texas Turfgrass Res. p. 36-38.

Tamminen, I., P. Makela, P. Heino, and E.T. Palva. 2001. Ectopic expression of $\mathrm{ABI} 3$ gene enhances freezing tolerance in response to abscisic acid and low temperature in Arabidopsis thaliana. Plant J. Cell Mol. Biol. 25:1-8.

Tan, W., T.J. Blake, and T.J.B. Boyle. 1992. Drought tolerance in faster-and slower-growing black spruce (Picea mariana) progenies: II. Osmotic adjustment and changes of soluble carbohydrate and amino acids under osmotic stress. Physiol Plant. 85:645-651.

Wang, Z. and B. Huang. 2001. Drought resistance of kentucky bluegrass in relation to ABA accumulation. Agron. Abstr. 328.

Wang, Z., B. Quebedeaux, and G.W. Stutte. 1995. Osmotic adjustment: Effect of water stress on carbohydrate in leaves, stems, and roots of apple. Austral. J. Plant Physiol. 22:747-754.

Wood, A.J. and P.B. Goldsbrough. 1997. Characterization and expression of dehydrins in water-stressed Sorghum bicolor. Physiol. Plant. 99:144-152.

Zhang, B. and D.D. Archbold. 1993. Solute accumulation in leaves of a Fragaria chiloensis and a $F$. virginiana selection responds to water deficit stress. J. Amer. Soc. Hort. Sci. 118:280-285.

Zhang, J., X. Zhang, and J. Liang. 1995. Exudation rate and hydraulic conductivity of maize roots are enhance by soil drying and abscisic acid treatment. New Phytol. 131:329-336. 